\title{
Optimal Use of MSWI Bottom Ash in Concrete
}

\author{
Tao Zhang*, and Zengzeng Zhao
}

(Received May 20, 2013, Accepted March 3, 2014)

\begin{abstract}
An experimental investigation was carried out to evaluate the mechanical properties of concrete mixtures in which coarse aggregate was partially (30, 50 or $70 \%$ ) replaced with pre-washed municipal solid waste incineration (MSWI) bottom ash. Results indicated that bottom ash reduced the compressive strength, elastic modulus, and levels of heavy metals in leachate when used as a replacement for gravel, and that the maximum amount of MSWI bottom ash in concrete should not exceed $50 \%$. To analyze the effect mechanism of bottom ash in concrete, the degree of hydration and the following pozzolanic reaction characterized by the pozzolanic activity index, and the porosity distribution in cement mortar. The study indicates that improved properties of concrete are not solely later strength gain and reduced levels of heavy metals in leachate but also the progression of pozzolanic reactions, where a dense structure contains a higher proportion of fine pores that are related to durability.
\end{abstract}

Keywords: concrete, municipal solid waste incineration bottom ash, compressive strength, elastic moduli, toxicity characteristic leaching procedure, pozzolanic activity index, mercury intrusion porosimetry, optimum use.

\section{Introduction}

With urbanization and industrialization, large amounts of municipal solid waste (MSW) have been generated. In 2030, the MSW in China will reach an astounding 4.8 billion tons with a forecasted annual growth rate of $10 \%$ (Cheng and $\mathrm{Hu}$ 2010). The incineration of MSW will likely become a feasible and effective management strategy. After incineration, waste is reduced by $85-90 \%$ in volume and $65-80 \%$ in mass (Valle-Zermeño et al. 2013). It is estimated that incineration generates about 3 million tons of MSWI ash each year in China (Yang et al. 2012).

Recycling of MSWIBA as a resource is important in that the major portion of the incineration by-products can be utilized. Chang et al. (1999) studied the possibility of replacing fine aggregates in concrete entirely with MSWI BA. The 28-day compressive strength of the MSW ash mixes was about $54.7 \%$ lower than that of normal sand mixes. Ferraris et al. (2009) investigated that the use of $20 \mathrm{wt} \%$ of VBA as cement filler or $75 \mathrm{vol} \%$ of VBA as a substitute for natural aggregate provided the same mechanical properties as those of reference samples. Sorlini et al. (2011) examined uses of calcareous Portland cement 42.5R and natural aggregate with $24 \%$ replacement by washed BA in concrete having a characteristic 28-day compressive strength of $20 \mathrm{MPa}$.

MSWI ash has also been studied as a possible cementitious material (Pecqueur et al. 2001; Li et al. 2012; Lam

School of Civil and Safety Engineering, Dalian Jiaotong University, Dalian 116028, China.

*Corresponding Author; E-mail: zht6977@163.com

Copyright ( $\odot$ The Author(s) 2014. This article is published

with open access at Springerlink.com et al. 2010). Juric et al. (2006) introduced $15 \mathrm{wt} \%$ of BA in the binder and $23 \mathrm{wt} \%$ of recycled aggregate in concrete and obtained a 28-day compressive strength of $40 \mathrm{MPa}$. Pan et al. (2008) introduced pre-washed $1.75 \mathrm{wt} \% \mathrm{FA}$ and $3.5 \mathrm{wt} \% \mathrm{BA}$ as a clay replacement in Type-II Portland cement production. Bertolini et al. (2004) found that a $30 \%$ replacement (by mass) of Portland cement with wet ground MSWI BA as mineral additive remarkably improved the strength and durability of concrete. Lee et al. (2008) extensively studied the 28-day compressive strength of the slag-cement mortar (composed of MSWI FA, scrubber ash and glass frit) was similar to that of ordinary cement mortar, and the 60- and 90-day compressive strengths were 2-11\% higher. Filipponi et al. (2003) proposed that enhancing the reactivity of bottom ash, either by increasing its specific surface area or by using appropriate chemical activators able to promote the development of pozzolanic reactions.

However, there is still an obstacle to substituting large fractions of materials with MSW ash (Chimenos et al. 1999). The well-known alkali-silica reaction (ASR) of BA related problems are thoroughly discussed in Bignozzi and Saccani (2012) and Müller and Rübner (2006). In addition to this, BA tends to undergo expansive and swelling reactions that are related to the presence of metallic aluminum or aluminum compounds (Müller and Rübner 2006). In order to reduce the secondary environmental pollution, some treatments have been proposed to reduce detrimental reactions (Gerven et al. 2005; Ferraris et al. 2009; Pera et al. 1997; Cheeseman et al. 2005; Chang et al. 1999).

In previous research, BA has often been studied combined with other waste as substitution materials used for concrete or mortar formulation; e.g., FA+BA (Ginés et al. 2009), contaminated soil+BA (Sorlini et al. 2011), colemanite waste+BA+FA (Kula et al. 2001), FA+scrubber BA+glass frit 
(Lee et al. 2008), and BA+recycled aggregate (Juric et al. 2006). BA alone has rarely been studied as a raw material in the formulation of cement and concrete. Additionally, BA has often been subjected to expensive treatment such as vitrification (Ferraris et al. 2009), dipping in sodium hydroxide (Pera et al. 1997), rapid sintering (Cheeseman et al. 2005) or refusederived fuel incineration (Chang et al. 1999). There have been few studies on the use of washed MSWI BA as the only substitution material. In these studies (Pera et al. 1997), the concrete with natural aggregate replaced by $50 \%$ of BA (treated with sodium hydroxide) provided a characteristic 28-day compressive strength of $25 \mathrm{MPa}$. When the high replacement percentage of the MSWI bottom ash is used, how to produce quality concrete is of significant research interest (Lin et al. 2008; Cheng 2012). In fact, BA is the sole substitution material of aggregate or cement, it is better to clarify reactions between the ash constituents and the cementitious binder and their possible effects on the performance, durability and environmental impact of the concrete. A more quantitative understanding of BA as the sole substitution material for different replacement ratios is needed.

The aim of the present work was to investigate the use of washed MSWI BA as a partial sole replacement for aggregate in concrete mixes and cement in mortar. Initially, the physical and chemical properties of the MSWI BA and the feasibility of using the MSWI BA as a construction material were investigated. To evaluate the effect of introducing BA into concrete, the compressive strength and elastic modulus were studied. The porosity of the mortar was measured to evaluate the properties of moisture transport, which may affect the durability of the concrete. Moreover, the environmental compatibility was studied by evaluating the leaching behavior of heavy metals under specified conditions.

\section{Experiments}

\subsection{Materials}

\subsubsection{Cement}

The cement used in this research was ordinary Portland cement type 425 (OPC). It was tested under the China Standard Specification GB175-2007 before being mixed. The results for the chemical composition and physical properties of the cement are given in Table 1 .

\subsubsection{Fine Aggregate}

Natural sand with maximum size of $5 \mathrm{~mm}$ was used as fine aggregate. Physical-property and sieve analyses were conducted according to GB/T 14684-2011, and the results are given in Tables 2 and 3, respectively. The size distribution of the sand is shown in Fig. 1.

\subsubsection{Coarse Aggregate}

The coarse aggregate used in this study had nominal particle size of $22 \mathrm{~mm}$, and was tested according to GB/T 14685-2011. The results of physical-property and sieve analyses are given in Tables 2 and 3, respectively. The size distribution of the gravel is shown in Fig. 2.

\subsubsection{MSWI BA}

MSWI BA was obtained from the Dalian MSW Incineration Plant. The furnace incinerator operates at temperatures between 950 and $1,150{ }^{\circ} \mathrm{C}$, processes approximately 1,200 tons of waste daily and generates $25 \mathrm{~kW}$ of electricity.

Approximately $20 \mathrm{~kg}$ of samples were taken from various locations in the MSWI pits of freshly quenched BA randomly each day. The sampling period lasted 1 month.

Table 1 Physical and chemical properties of the cement used in this study.

\begin{tabular}{|c|c|c|}
\hline Physical or chemical test & Result obtained & GB175-2007 specification \\
\hline Fineness $(80 \mu \mathrm{m})$ & $8.5 \%$ & $<10 \%$ \\
\hline Specific surface $\left(\mathrm{m}^{2} / \mathrm{kg}\right)$ & 355 & $300-450$ \\
\hline \multicolumn{3}{|c|}{ Setting time $(\mathrm{min})$} \\
\hline Initial & 113 & $>90$ \\
\hline Final & 389 & $<600$ \\
\hline \multicolumn{3}{|c|}{ Compressive strength (MPa) } \\
\hline 3 days & 17.4 & $>16.0$ \\
\hline 28 days & 44 & $>42.5$ \\
\hline Specific gravity $\left(\mathrm{kg} / \mathrm{m}^{3}\right)$ & 3.20 & - \\
\hline Standard consistency water requirement & $28 \%$ & $<30 \%$ \\
\hline $\mathrm{C}_{3} \mathrm{~A}$ & $3.2 \%$ & $<9.0 \%$ \\
\hline $\mathrm{C}_{4} \mathrm{AF}$ & $7.1 \%$ & $<12.0 \%$ \\
\hline $\mathrm{MgO}$ & $2.2 \%$ & $<6.0 \%$ \\
\hline $\mathrm{Na}_{2} \mathrm{O}+0.658 \mathrm{~K}_{2} \mathrm{O}$ & $0.12 \%$ & $<0.6 \%$ \\
\hline
\end{tabular}

- Denotes there is no limit specified. 
Table 2 Physical properties of aggregates.

\begin{tabular}{c|c|c}
\hline Properties & Fine aggregate (specification) & Coarse aggregate (specification) \\
\hline \hline Specific gravity $\left(\mathrm{kg} / \mathrm{m}^{3}\right)$ & $2,560(>2,500)$ & $2,698(>2,500)$ \\
\hline Fineness modulus & $2.7(2.0-3.5)$ & $1.11(-)$ \\
\hline Saturated surface dry absorption (\%) & $0.89(-)$ & $40.1(<47)$ \\
\hline Void $(\%)$ & $37.1(<47)$ & $1,624(>1,500)$ \\
\hline Unit weight $\left(\mathrm{kg} / \mathrm{m}^{3}\right)$ & $1,720(>1,500)$ & $28.7(<31.5)$ \\
\hline Maximum particle size $(\mathrm{mm})$ & $4.75(-)$ & \\
\hline
\end{tabular}

Table 3 Sieve analysis of aggregates.

\begin{tabular}{|c|c|c|c|c|c|}
\hline \multicolumn{3}{|c|}{ Fine aggregate } & \multicolumn{3}{|c|}{ Coarse aggregate } \\
\hline \multirow[t]{2}{*}{ Sieve size } & Percent & $\mathrm{GB} / \mathrm{T}$ & \multirow[t]{2}{*}{ Sieve size $(\mathrm{mm})$} & \multirow{2}{*}{$\begin{array}{l}\text { Percent } \\
\text { Passing } \\
\end{array}$} & \multirow{2}{*}{$\begin{array}{c}\mathrm{GB} / \mathrm{T} \\
14685-2011 \\
\end{array}$} \\
\hline & Passing & $14684-2011$ & & & \\
\hline $4.75 \mathrm{~mm}$ & 1.6 & $0-10$ & 31.5 & 0.8 & $0-5$ \\
\hline $2.36 \mathrm{~mm}$ & 18.7 & $0-25$ & 26.5 & 14.3 & $20-35$ \\
\hline $1.18 \mathrm{~mm}$ & 45.7 & $10-50$ & 19.0 & 48.2 & $40-60$ \\
\hline $600 \mu \mathrm{m}$ & 68.4 & $41-70$ & 16.0 & 66.3 & $60-75$ \\
\hline $300 \mu \mathrm{m}$ & 91.4 & $70-92$ & 9.50 & 77.8 & $75-90$ \\
\hline \multirow[t]{2}{*}{$150 \mu \mathrm{m}$} & 99.7 & $90-100$ & 4.75 & 98.8 & $90-100$ \\
\hline & & & 2.36 & 99.9 & $95-100$ \\
\hline
\end{tabular}

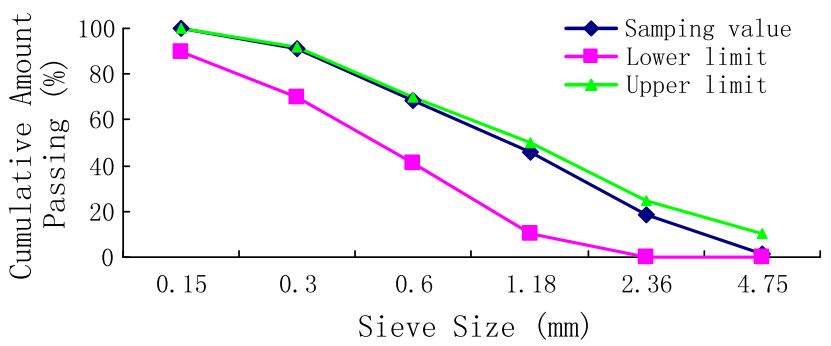

Fig. 1 Particle size distribution of sand.

Because wet ground MSWI BA has been shown to have good pozzolanic behavior and make a significant contribution to the development of the strength, impermeability, elastic modulus and the absence of expansion of concrete (Cheng 2012), the MSWI BA was treated by a wet grinding process. The water used for wet grinding was introduced in the concrete mix (as part of the mixing water), and thus no residues were produced. The chemical composition of BA was analyzed using an X-ray fluorescence spectrometer. The size distribution and mineralogical composition are presented in Figs. 3 and 4 respectively. The physical properties of the BA are given in Table 4. The average chemical composition present in the MSWI BA is given in Table 5.

\subsection{Preparation and Casting of Test Specimens}

Different concrete mixtures were produced by a partial replacement of gravel with MSWI BA; the concrete mixture compositions are given in Table 6. (Concrete mixtures B23, B25 and B27 were made with the raw BA and the other mixtures with the washed BA.) Three series of mixtures and control concrete were prepared according to GB50081-2002 standards.

Natural aggregate (sand and gravel) blended with wet ground MSWI BA was mixed homogeneously with cement and water in a mixer. The replacement levels of the gravel were $0,30,50$ and $70 \%$ by weight. The sand ratio was set to 0.38 , and the water/cement $(\mathrm{w} / \mathrm{c})$ ratio of the concrete was $0.45,0.51$ or 0.55 .

Results from various investigations have revealed that the bottom ash has low chemical reactivity (Filipponi et al. 2003). Thus, further studies were aimed at investigating the reactivity of BA and the effect mechanism of the BA in concrete. MSWI BA was ground and ball-milled into fine powder with particle size less than $40 \mu \mathrm{m}$ to partly $(10,20$ and $30 \%$ ) replace the cement. The specific surface of the BA powder is $425 \mathrm{~m}^{2} / \mathrm{kg}$, according to the GB/T14685-2011 specifications. The cement mortar was prepared according to JGJ/T70-2009, and detailed information of the cement mortar mixtures is listed in Table 8 .

Density and working ability (measured in a slump test) of the fresh concretes were obtained according to JGJ/T702009. The setting time of the cement mortar was measured using the Vicat needle test. The densities of the reference mixture and concrete mixtures are compared in Fig. 5 $(\mathrm{w} / \mathrm{b}=0.51)$. According to JGJ/T70-2009 and GB/T176711999, concrete and cement mortar cubes were cured for periods ranging from 7 to 90 days. After the curing period, the concrete and cement mortar were subjected to the following tests. 
Table 4 Physical properties of the MSWI BA.

\begin{tabular}{|c|c|c|c|}
\hline Sieve size $(\mathrm{mm})$ & Particle size distribution (\%) & Sieve size $(\mathrm{mm})$ & Particle size distribution (\%) \\
\hline 31.500 & 0.67 & 2.500 & 69.12 \\
\hline 26.500 & 2.28 & 1.250 & 78.67 \\
\hline 19.000 & 5.97 & 0.630 & 90.35 \\
\hline 16.000 & 8.64 & 0.315 & 96.21 \\
\hline 10.000 & 21.15 & 0.160 & 98.67 \\
\hline 5.000 & 46.05 & & \\
\hline \multicolumn{2}{|c|}{ Specific gravity $\left(\mathrm{kg} / \mathrm{m}^{3}\right)$} & 2,210 & \\
\hline Fineness modulus & & 3.76 & \\
\hline Unit weight $\left(\mathrm{kg} / \mathrm{m}^{3}\right)$ & & 2,145 & \\
\hline Water absorption (\%) & & $10.74(24 \mathrm{~h})$ & \\
\hline
\end{tabular}

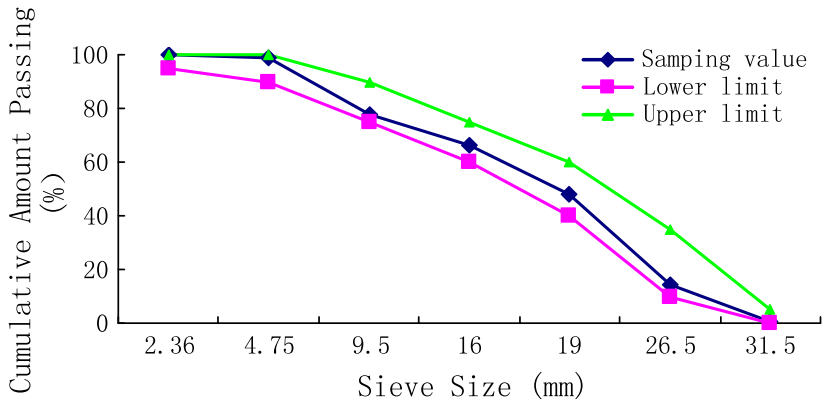

Fig. 2 Particle size distribution of gravel.

\subsection{Hardened Concrete}

To evaluate the effect of MSWI BA in concrete, three characteristics were investigated: the compressive strength and elastic modulus of the hardened concrete, and the leaching behavior as assessed in a toxicity characteristic leaching procedure (TCLP) test.

(1) Unconfined compressive strength The unconfined compressive strength was measured according to JGJ/ T70-2009. The compressive strengths of concrete mixes made with and without BA were determined at $7,14,28,60$, and 90 days of curing. The test results are given in Table 6 and shown in Fig. 6.

(2) Elastic modulus The property was assessed employing the standard methods given in JGJ/T70-2009. The

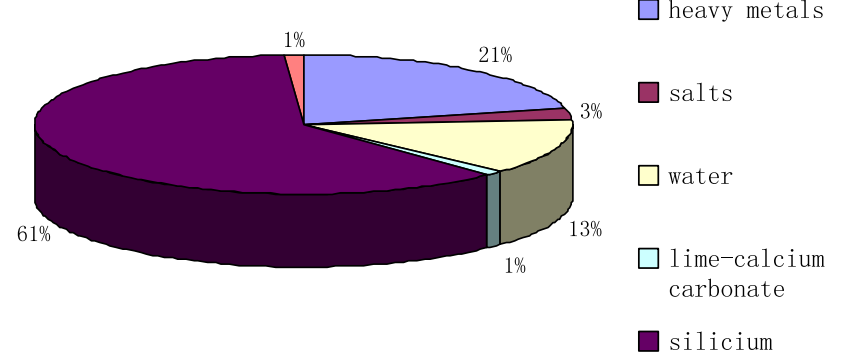

Fig. 4 Mineralogical composition of the MSWI BA.

development of the elastic modulus between days 7 and 90 is presented in Fig. 7.

(3) Leaching behavior The TCLP test estimates landfill conditions to determine the mobility of toxic contaminants and sets limits to determine whether the material under scrutiny is toxic. Solid waste must be evaluated before landfilling or reused to avoid the leaching of heavy metal ions and consequent pollution.

The leaching procedure used in this study followed the test method SW 846 1311-TCLP of the United States Environmental Protection Agency. The test for MSWI BA was carried out on a sample crushed to a particle size of less than $4 \mathrm{~mm}$. In the test for concrete cured for 28 days, concrete was broken into several pieces, and a piece from the heart of

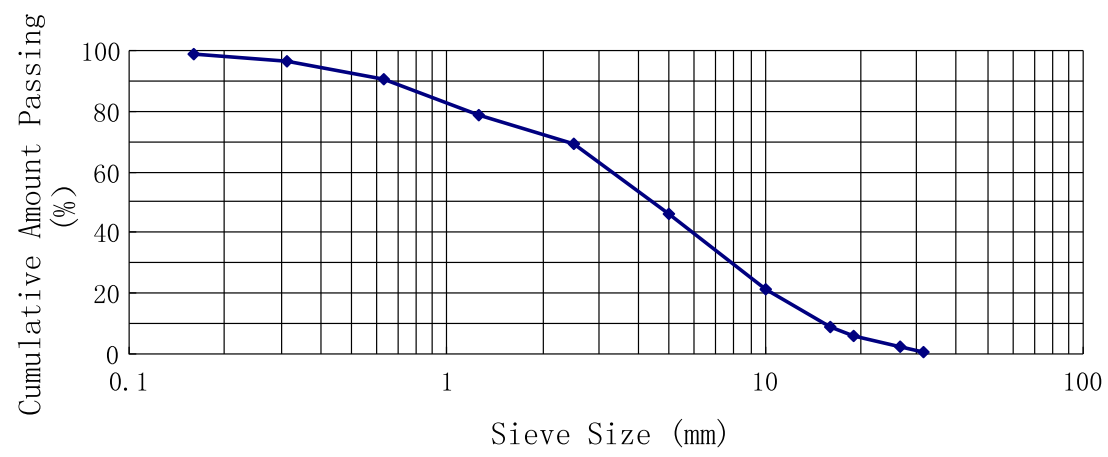

Fig. 3 Size distribution of the MSWI BA.

176 | International Journal of Concrete Structures and Materials (Vol.8, No.2, June 2014) 
Table 5 Chemical composition of the MSWI BA.

\begin{tabular}{c|c|c|c}
\hline Oxides & Amount (\%) & Minor metal element & Amount (mg/kg) \\
\hline $\mathrm{Al}_{2} \mathrm{O}_{3}$ & 7.4 & $\mathrm{Ca}$ & 52,336 \\
\hline $\mathrm{Na}_{2} \mathrm{O}$ & 11.3 & $\mathrm{Na}$ & 11,472 \\
\hline $\mathrm{K}_{2} \mathrm{O}$ & 1.8 & $\mathrm{Kg}$ & 4,129 \\
\hline $\mathrm{SO}_{3}$ & 1.1 & $\mathrm{~Pb}$ & 7,238 \\
\hline $\mathrm{CaO}$ & 15.7 & $\mathrm{Cd}$ & 37 \\
\hline $\mathrm{Fe}_{2} \mathrm{O}_{3}$ & $\mathrm{Cr}$ & 203 \\
\hline $\mathrm{MgO}$ & 10.2 & $\mathrm{Cu}$ & 5,578 \\
\hline $\mathrm{MnO}$ & 1.7 & $\mathrm{Zn}$ & 3,047 \\
\hline $\mathrm{P}_{2} \mathrm{O}_{5}$ & 0.14 & $\mathrm{Al}$ & 17,356 \\
\hline $\mathrm{TiO}_{2}$ & 1.60 & $\mathrm{Fe}$ & 22,410 \\
\hline $\mathrm{SiO}_{2}$ & 0.33 & 58.1 & \\
\hline
\end{tabular}

Table 6 Detailed information of the mixtures.

\begin{tabular}{|c|c|c|c|c|c|c|c|c|c|c|c|}
\hline \multirow[t]{2}{*}{ Mixture } & \multirow[t]{2}{*}{$\mathrm{w} / \mathrm{c}$} & \multirow{2}{*}{$\begin{array}{l}\text { Cement } \\
\left(\mathrm{kg} / \mathrm{m}^{3}\right)\end{array}$} & \multirow{2}{*}{$\begin{array}{c}\text { Water } \\
\left(\mathrm{kg} / \mathrm{m}^{3}\right)\end{array}$} & \multirow{2}{*}{$\begin{array}{l}\text { Density } \\
\left(\mathrm{kg} / \mathrm{m}^{3}\right)\end{array}$} & \multirow[t]{2}{*}{ BA (\%) } & \multirow{2}{*}{$\begin{array}{c}\text { Slump } \\
(\mathrm{min})\end{array}$} & \multicolumn{5}{|c|}{ UCM (MPa) } \\
\hline & & & & & & & 7 days & 14 days & 28 days & 60 days & 90 days \\
\hline $\mathrm{R} 1$ & 0.45 & 320 & 175 & 1,850 & 0 & 23 & 28.2 & 31.1 & 36 & 40.7 & 41.8 \\
\hline A13 & 0.45 & 320 & 203.7 & 2,030 & 30 & 21 & 23.6 & 28.3 & 35.6 & 40.9 & 42.1 \\
\hline A15 & 0.45 & 320 & 223 & 2,180 & 50 & 18 & 20.7 & 26.9 & 35.1 & 37.3 & 39.6 \\
\hline A 17 & 0.45 & 320 & 242 & 2,230 & 70 & 11 & 18.2 & 24.3 & 31 & 36.5 & 38.6 \\
\hline $\mathrm{R} 2$ & 0.51 & 320 & 175 & 1,910 & 0 & 25 & 24.3 & 30.4 & 36.7 & 40.4 & 41.8 \\
\hline A 23 & 0.51 & 320 & 206 & 2,070 & 30 & 22 & 22 & 26.9 & 35.8 & 40.7 & 42.3 \\
\hline A 25 & 0.51 & 320 & 224.8 & 2,170 & 50 & 18 & 19.7 & 24.3 & 32.9 & 39.6 & 41.2 \\
\hline $\mathrm{A} 27$ & 0.51 & 320 & 228.1 & 2,220 & 70 & 12 & 12.5 & 20.2 & 28 & 34.3 & 36.7 \\
\hline B23 & 0.51 & 320 & 205.7 & 2,070 & 30 & 22 & 19.4 & 22.5 & 27.6 & 32.8 & 33.9 \\
\hline $\mathrm{B} 25$ & 0.51 & 320 & 225 & 2,171 & 50 & 19 & 17.1 & 19.8 & 25.4 & 32 & 34.3 \\
\hline B27 & 0.51 & 320 & 242 & 2,218 & 70 & 14 & 10.8 & 14.5 & 19 & 26.1 & 28.5 \\
\hline $\mathrm{R} 3$ & 0.55 & 320 & 175 & 1,950 & 0 & 28 & 16.2 & 23.3 & 29.9 & 35.5 & 37.1 \\
\hline A33 & 0.55 & 320 & 209 & 2,060 & 30 & 22 & 15.6 & 20.3 & 22.7 & 24.5 & 25.4 \\
\hline A35 & 0.55 & 320 & 231.6 & 2,130 & 50 & 15 & 14.3 & 19.1 & 21.8 & 24 & 24.7 \\
\hline A37 & 0.55 & 320 & 240 & 2,210 & 70 & 9 & 12.2 & 17.4 & 18.3 & 18.7 & 19.1 \\
\hline
\end{tabular}

UCM denotes unconfined compressive strength.

the concrete was taken as the test sample (average size of $9 \mathrm{~mm}$ ) (Bertolini et al. 2004).

The $\mathrm{pH}$ values of granular samples were more than 5 . Accordingly, specimens were agitated with glacial acetic acid buffer solution \#B (pH $2.88 \pm 0.05)$ for $18 \mathrm{~h}$ at a temperature of $25^{\circ} \mathrm{C}$ maintaining a 1:10 sample-to-fluid ratio at a frequency of $130 \mathrm{r} / \mathrm{min}$. After agitation, leachates were collected by $0.8-\mathrm{mm}$ glass fiber filters and the leachates were preserved in $2 \% \mathrm{HNO}_{3}$. The concentrations in the filtrate were determined by inductively coupled plasmaatomic emission spectrometry (Müller and Rübner 2006).
The leaching toxicities of heavy metals in the crushed hardened concrete are given in Table 7.

\subsection{Cement Paste}

Mechanical and physical analyses of cement pastes were conducted at different ages as follows.

(1) Setting time The fresh cement pastes were measured in a Vicat needle test (JGJ/T70-2009), and the water demand was obtained according to JGJ/T70-2009. The results are presented in Table 8 . 
(2) Pozzolanic activity index The laboratory testing program was that specified by ASTM Designation C 311 . The compressive strengths of the control specimens

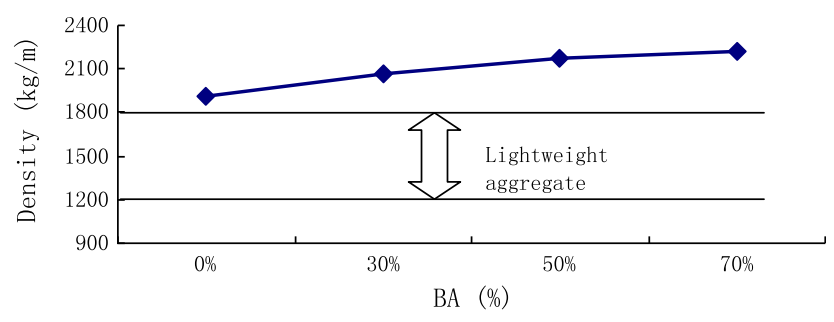

Fig. 5 Density of the reference mixture.

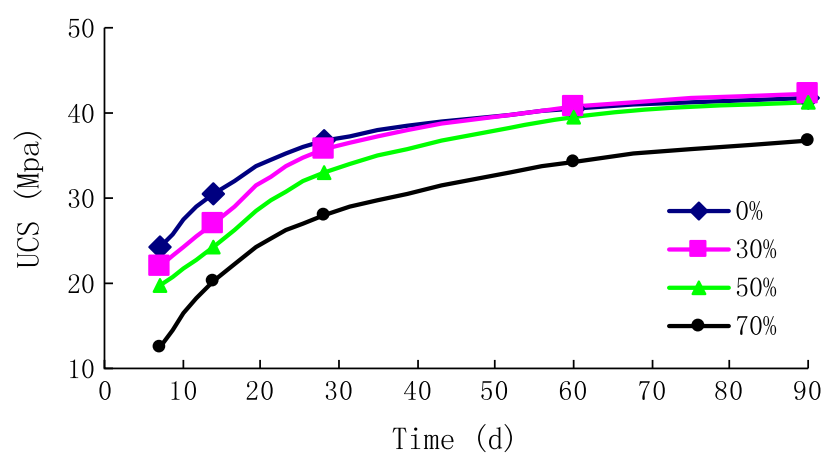

Fig. 6 Development of compressive strength with time $(w / b=0.51)$.

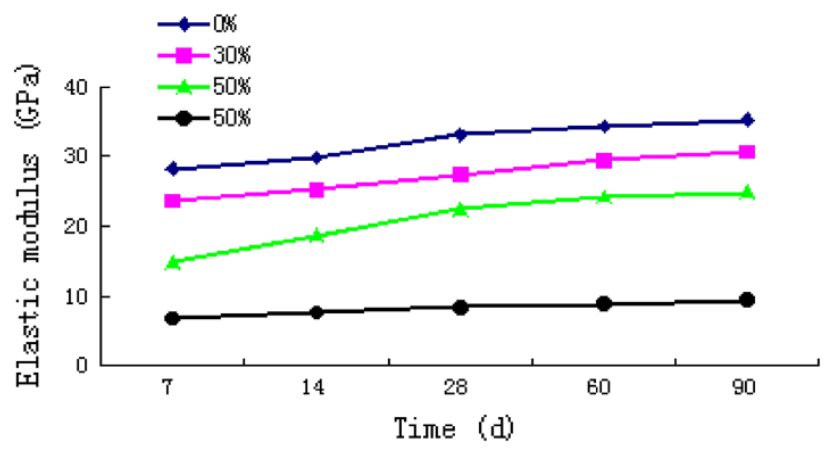

Fig. 7 Development of the elastic modulus with time $(\mathrm{w} / \mathrm{c}=0.51)$ and test specimens were determined at an age of 28 days. The pozzolanic activity index was calculated as

Pozzolanic activity index $=\mathrm{A} / \mathrm{B} \times 100$,

where $\mathrm{A}$ is the average compressive strength of the test specimen $(\mathrm{Pa})$ and $\mathrm{B}$ is the average compressive strength of the control specimen $(\mathrm{Pa})$.

(3) Pozzolanic activity Pozzolanic activity was evaluated for BA in a suspension for 7 and 14 days at $40{ }^{\circ} \mathrm{C}$ and relative humidity of $100 \%$. The suspension was filtered, and the $\mathrm{CaO}$ content and total alkalinity were analyzed. By measuring the $\mathrm{Ca}(\mathrm{OH})_{2}$ content, the degree of hydration of the cement can be determined. A point measured below the solubility curve shows that $\mathrm{Ca}(\mathrm{OH})_{2}$ is consumed by additional reactions. If so, the examined material can hardly be described as pozzolanic.

(4) Mercury intrusion porosimetry The pore size distribution and porosity of the hardened pastes were surveyed by mercury intrusion porosimetry. Micropores were analyzed using a gas-adsorption Autopore III-9420 Mercury Intrusion Porosimeter.

\section{Results and Discussion}

\subsection{Cement}

The chemical compositions and physical properties of the cement are listed in Table 1. The physical and chemical properties of the cement met the requirements of GB1752007.

\subsection{Fine Aggregate}

The properties of the sand are listed in Table 2. Sieve analysis results are presented in Table 3, and the corresponding size distribution of the sand is presented in Fig. 1. Physical properties met the requirements of $\mathrm{GB} / \mathrm{T}$ 14684-2011.

Table 7 TCLP analysis of materials and concrete mixtures.

\begin{tabular}{c|c|c|c|c|c}
\hline \multirow{2}{*}{ Element } & \multicolumn{5}{|c}{ TCLP test value (mg/L) } \\
\cline { 2 - 6 } & MSWI & WMSWI & B23 (28 days) & A23 (28 days) & TCLP levels \\
\hline \hline $\mathrm{Cu}$ & 1.69 & 0.64 & 0.29 & 0.27 & 0.35 \\
\hline $\mathrm{Zn}$ & 0.66 & 0.72 & 0.67 & 0.04 & 5 \\
\hline $\mathrm{Pb}$ & 0.069 & 0.32 & 0.13 & 0.14 & 1 \\
\hline $\mathrm{Cd}$ & 0.45 & 0.26 & 0.21 & 0.02 & 5 \\
\hline $\mathrm{Cr}$ & 0.17 & 0.06 & 0.06 & 0.10 & 5 \\
\hline $\mathrm{Ni}$ & 0.15 & 0.15 & 0.15 & N.D. & 5 \\
\hline $\mathrm{Ba}$ & 0.58 & 0.34 & 0.04 & 5 \\
\hline $\mathrm{As}$ & 0.21 & 0.13 & & & 5 \\
\hline
\end{tabular}

N.D. means not detectable. 
Table 8 Water demand for normal consistency and setting times.

\begin{tabular}{|c|c|c|c|c|c|c|c|c|}
\hline \multirow[t]{2}{*}{ Sample } & \multicolumn{2}{|c|}{ Substitution level (\%) } & \multirow{2}{*}{$\begin{array}{c}\text { Water demand } \\
(\%)\end{array}$} & \multicolumn{2}{|c|}{ Setting time (min) } & \multicolumn{2}{|c|}{ UCS (MPa) } & \multirow{2}{*}{\begin{tabular}{|c|} 
Pozzolanic \\
activity index \\
$(\%)$
\end{tabular}} \\
\hline & OPC & $\mathrm{BA}$ & & Initial & Final & 7 days & 28 days & \\
\hline $\mathrm{C} 0$ & 100 & 0 & 26.1 & 179 & 230 & 23.4 & 42.6 & \\
\hline $\mathrm{C} 1$ & 90 & 10 & 26.5 & 196 & 248 & 23.8 & 40.24 & 94.46 \\
\hline $\mathrm{C} 2$ & 80 & 20 & 27.4 & 228 & 268 & 24.6 & 37.66 & 88.4 \\
\hline $\mathrm{C} 3$ & 70 & 30 & 28.8 & 240 & 295 & 25.3 & 33.87 & 79.5 \\
\hline $\mathrm{C} 4$ & 50 & 50 & 30.1 & 253 & 321 & 21.9 & 24.8 & 58.2 \\
\hline
\end{tabular}

\subsection{Coarse Aggregate}

The physical properties listed in Table 3 met the requirements of GB/T 14685-2011. The sieve analysis and size distribution are presented in Table 3 and Fig. 1, respectively.

\subsection{MSWI BA}

The size distribution is presented in Fig. 3. According to JTGF30-2003, the curve shows that the material qualifies for direct use in an embankment or road during road construction. The physical properties in Table 3 meet the requirements of GB/T 14685-2011 (Table 4).

The composition of the MSWI BA used in this study was analyzed and is summarized in Table 5. It is seen that the BA is mainly composed of $\mathrm{Si}, \mathrm{Al}$ and $\mathrm{Ca}$ oxides, accounting for $81.2 \%$ of the material on a dry-weight basis. The high Si and $\mathrm{Al}$ contents and the amorphous nature of the major phases in BA suggest the possible pozzolanic activity of the material. Heavy metals of environmental concern present at relatively high concentrations include $\mathrm{Cu}, \mathrm{Zn}, \mathrm{Pb}, \mathrm{Cd}$ and $\mathrm{Cr}$. The TCLP leaching concentrations of the target metals of raw MSWI BA are all lower than regulatory thresholds of the United States Environmental Protection Agency.

\subsection{Fresh Concrete}

Table 6 gives the values of slump and density for the fresh concrete. Concrete with the addition of MSWI BA had remarkably reduced workability. This is possibly because the $\mathrm{BA}$ is a material with higher water absorptivity, higher natural air content, and a large portion of small particles, which would negatively affect the consistency of the concrete.

Figure 5 compares the density of concrete mixture and that of the light-weight aggregate concrete. The compressive strength of the concrete mixture are shown in Fig. 6 (water cement ratio of 0.51 ). It is noted that the density of the concrete mixture is higher than the density of the lightweight aggregate concrete, while the density of the MSWI BA used is lower than that of the gravel. This is attributed to the water absorption rate of the MSWI BA being far greater than that of the gravel.

\subsection{Hardened Concrete}

\subsubsection{Unconfined Compressive Strength}

The values of compressive strengths results obtained at ages of 7, 14, 28, 60 and 90 days are summarized in Table 7.
The compressive strength of mixtures B23, B25 and B27 (dosage of raw BA) was $69 \%$ lower than that of the reference mixture (R2). The washing of BA reduced this difference from the reference mixture. Bertolini et al. suggested that reactive aluminum particles react in a high-pH environment producing $\mathrm{H}_{2}$ gas during the wet grinding process, resulting in a reduced amount of $\mathrm{H}_{2}$ gas bubbles in concrete as there are not enough reactive aluminum particles left in the concrete mix.

The dependence of compressive strength on the content mixtures is presented in Fig. 6 (taking the water cement ratio of 0.51 as an example). It is noted that the compressive strength at an early age (1-28 days) decreases with replacement. At ages of 60 and 90 days, the concrete mixture A25 showed close results to the reference mixture, A23 had the higher value of the compressive strength, and A27 had the lower value of the compressive strength. Negative effect on early strength development may be due to the weaker aggregate and delays in the hydration of cement (since the quantity of $\mathrm{CaO}$ is insufficient for the formation of all cementitious compounds) as the content is increased (Juric et al. 2006). The slope of the curve represents the rate of increase in strength; because the hydration of cementitious materials is a time-dependent process, it was expected that the slope would steepen with elapsed time. However, it is interesting to observe that the slope slightly decreased with time. This might indicate that BA develops strength in the later stage of hydration in contrast to the case for OPC 42.5 R (Juric et al. 2006). Concrete mixtures having $70 \%$ replacement levels of BA developed less compressive strength. The lower later strength development was due to the dilution effect, which resulted in insufficient calcium hydroxide for pozzolanic reactions.

Increasing the percentage weight of MSWI BA in the concrete had a great effect on early strengths. Hence, the acceptable level of MSWI BA replacement was established to be $50 \%$ to ensure the strength property of the concrete. (The requirement for building concrete is characteristic 28-day strength of $25 \mathrm{MPa}$ ). To investigate the strong evidence of pozzolanic behavior, it is better to calculate the activity index discussed below.

\subsubsection{Elastic Modulus Test}

Figure 7 shows the increase in the concrete elastic modulus as a function of time for different mixes $(\mathrm{w} / \mathrm{b}=0.51)$. 
The figure reveals that the modulus of elasticity of the concrete mixtures was lower than that of the control mix at all ages, and the modulus of elasticity continued to decrease with an increase in the amount of MSWI BA. However, it concluded that the level of the modulus of elasticity tended to decline with the replacement of the MSWI BA. The $50 \%$ replacement of gravel by MSWI BA in concrete resulted in deterioration of the elastic modulus evolution. Hence, the replacement with MSWI BA should not be more than $50 \%$.

\subsubsection{TCLP}

Raw material, as shown in Table 7, contains high concentrations of $\mathrm{Cu}, \mathrm{Cd}, \mathrm{Zn}$ and $\mathrm{Ba}$. Table 7 also presents leachate analysis data for washed BA and concrete mixtures after exposure to distilled buffer solution B. In general, the washing process significantly reduced the levels of leaching of most metals and particularly the level of leaching of $\mathrm{Cu}$. However, the data also indicate increased leaching of Pd and $\mathrm{Zn}$ under the test conditions, although the leaching levels remain low and further data are needed to confirm this effect.

The cement matrix is known to be more stable than phases of raw materials. Heavy metals were mostly retained and incorporated into the cement matrix, as shown in Table 7, and the TCLP leaching concentrations of the target metals of concrete mixtures were all lower than TCLP thresholds. There was very little difference in metal leaching between concrete mixtures B23 and A23, because of both the high metal concentration in the raw waste and the low $\mathrm{pH}$ value of the leaching solution. Previous work has shown that higher temperatures and longer dwell times are needed to significantly reduce metal leaching from MSWI BA (Cheeseman et al. 2005). Therefore, if it is necessary, the waste plant could employ the process of melting and solidification, thus stabilizing metallic compounds in the 'molecular' structure of the waste product and preventing them from leaching out and dispersing into the surrounding environment.

\subsection{Mortar Paste \\ 3.7.1 Water Demand for Normal Consistency and Setting Time}

Table 8 reveals that MSWI BA delayed both the initial and final setting times compared with the times for OPC, particularly for high replacement levels. Both initial and final setting times increased with the amount of cement replaced with the fine MSWI BA. At waste dosages less than $50 \%$, the initial setting time was 17-61 min longer for the mixture than for the ordinary cement mortar and the final setting time was 18-65 min longer for the mixture than for the ordinary cement mortar. The variation was so small that it will hardly affect the requirements of construction. However, when the addition of MSWI BA was increased further to $50 \%$, there was a significant increase in the setting times, particularly the final setting time, compared with those of the reference mortar $(\mathrm{C} 0)$. Experimental results indicated that the observed delay in the setting times may be primarily attributed to the rate of the pozzolanic reactions (Lin et al. 2008).

The water demand for normal consistency is given in Table 8. As seen in Table 2, the incorporation of MSWI BA slightly increases the water demand for normal consistency, and increases with increasing content of MSWI BA. When the replacement of MSWI BA was beyond $50 \%$, the water demand for normal consistency was about $15.3 \%$ higher. Consequently, in the experimental study of the mortar paste, the content of MSWI BA incorporated into blended cement was controlled below $50 \%$.

\subsubsection{Pozzolanic Activity}

At an age of 28 days, reference mortar $(\mathrm{C} 0)$ had the highest compressive strength of the matrices tested. In addition, the matrices with fine MSWI BA $(\mathrm{C} 1, \mathrm{C} 2)$ had results similar to those of $\mathrm{C} 0$. $\mathrm{C} 4$ mortar had deteriorated strength evolution. The poor performance of $\mathrm{C} 4$ is due to the high content of BA, which did not contribute sufficiently to the strength at an early age because of its relatively low reactivity. The hydration of cement was thus increasingly delayed as the content increased. However, the pozzolanic activity index after 28 days for $30 \%$ replacement was $79.5 \%$, which exceeded the level of $70 \%$ in Chinese National Standard GB/T 1596-2005, and the mixture could be used as an active admixture under particular conditions. However, the ratio of the strength for $50 \%$ replacement to the strength of the reference was $58.2 \%$, which is less than the requirement of $65 \%$ of GB/T 2847-2005. From this perspective, the incorporation of MSWI BA in concrete should be controlled below $30 \%$.

$\mathrm{X}$-ray diffraction analysis of OPC pastes showed that the main hydration products in the pastes were $\mathrm{Ca}(\mathrm{OH})_{2}, \mathrm{C}-\mathrm{S}-\mathrm{H}$ (tobermorite) and $\mathrm{C}-\mathrm{A}-\mathrm{H}$ (calcium aluminate hydrate), and that the environment of hydration and the next pozzolanic reaction is alkaline. We therefore determined the degrees of cement hydration and pozzolanic reaction from the concentrations of $\mathrm{CaO}$ and $\mathrm{OH}^{-}$.

From Fig. 8, the $\mathrm{Ca}(\mathrm{OH})_{2}$ content in almost all mixtures decreases as the bottom ash content and curing age increase. The measured points of C0 (both 7 and 14 days) lie on the saturation curve, meaning that the suspension is saturated. Except for $\mathrm{C} 0$ and $\mathrm{C} 1$ (7 days), all measurement points lie below the saturation curve, indicating the mixtures had pozzolanic behavior. The only measurement point of 7 days for which the mixture containing $10 \%$ of the bottom ash is above the saturation curve is probably due to the very low active silica content of this sample (Antiohos and Tsimas 2007). Moreover,

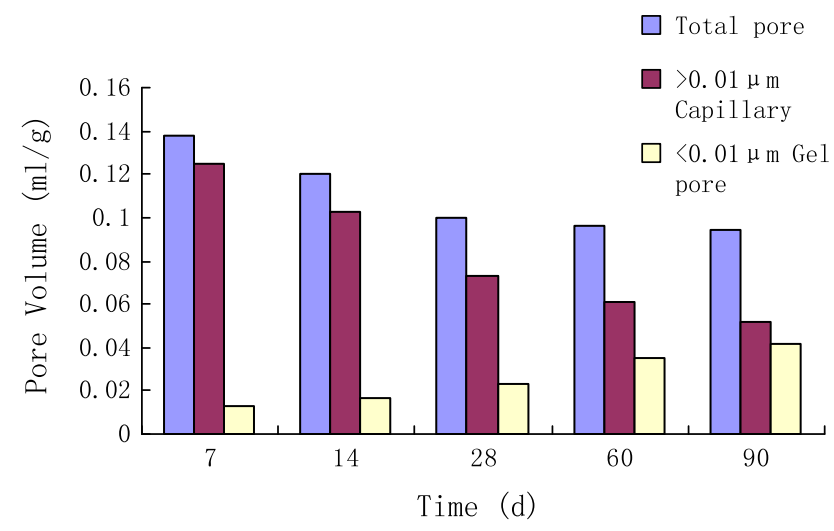

Fig. 8 Graph assessing Pozzolanic activity (BA denotes BA). 


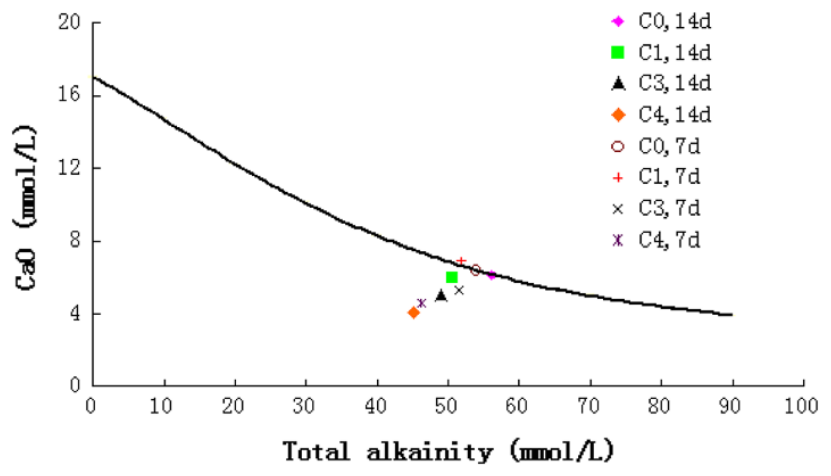

Fig. 9 Porosity distribution in OPC (W/S = 0.51).

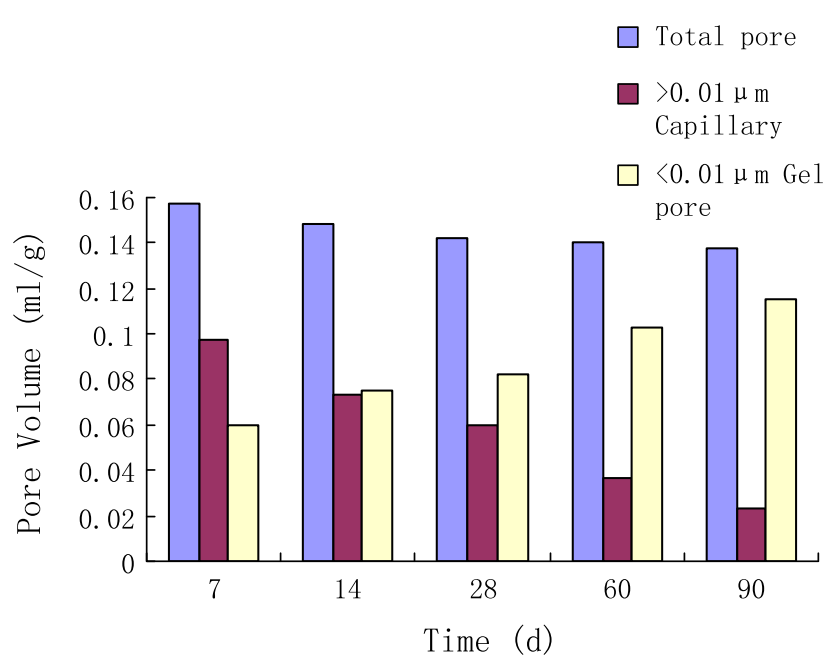

Fig. 10 Porosity distribution in the cement samples blended with MSWI bottom-ash powder (30\% substitution) $(\mathrm{W} / \mathrm{S}=0.51)$.

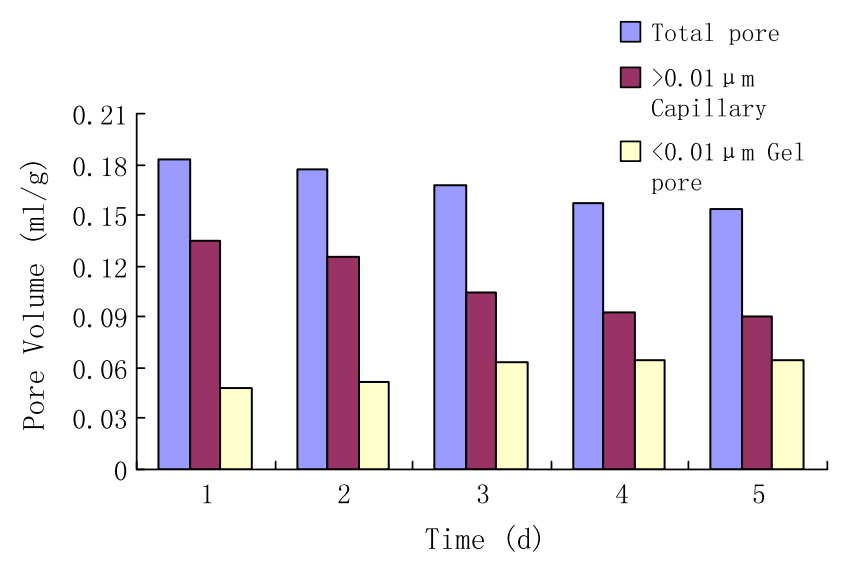

Fig. 11 Porosity distribution in the cement samples blended with MSWI bottom-ash powder (50\% substitution) $(\mathrm{W} / \mathrm{S}=0.51)$.

the high content of $\mathrm{BA}$, because of its relatively low reactivity, greatly reduced the quantity of $\mathrm{C}_{3} \mathrm{~S}, \mathrm{C} 3 \mathrm{~A}$ and $\mathrm{C}_{2} \mathrm{~S}$, which did contribute sufficiently to the degree of hydration. Therefore, the limit of MSWI bottom ash replacement of concrete was $30 \%$.

\subsubsection{Mercury Intrusion Porosimetry}

Figures 9, 10 and 11 show the porosity distribution in the OPC and blended paste samples (replacement levels of 30 and
$50 \%$ ). It was observed that porosity decreased in all samples with an increasing hydration period, and the pore size distribution varies markedly between the OPC and fine MSWI bottom-ash pastes. At later ages, however, the fine MSWI bottomash paste samples tend to possess more fine pores $(<10 \mathrm{~nm})$ than the OPC paste samples. Because the hydraulic materials gradually filled in large pores with the hydration products, capillary pores being filled with $\mathrm{C}-\mathrm{S}-\mathrm{H}$ gels, containing much finer gel pores, formed via latent hydraulic reactions. This hypothesis is supported by the fact that the enhancement of later strength coincides with the shift in pore size.

\section{Conclusion}

The following conclusions are drawn from the results of the study.

(1) Generally, MSWI BA has better characteristics if it has undergone a washing treatment. From either a technical or environmental point of view, the physical properties of fresh and hardened concrete are not deteriorated by the presence of pre-washed MSWI BA.

(2) MSWI BA affected the mechanical properties of the concrete mixtures tested. For less than $50 \%$ of replacement of gravel with MSWI BA, the characteristic 28-day compressive strength of the mixture (25 $\mathrm{MPa}$ ) meets the requirement for building concrete.

(3) The slower early strength development followed by higher strength development is characteristic of the MSWI BA containing a latent hydraulic material. The concentration of heavy metals leaching out from the concrete was reduced by the solidification mechanism. MSWI BA was effective in solidifying and stabilizing the matrix.

(4) The present investigation revealed the low chemical reactivity of BA and that BA is suitable as a cement substitute. Initial and final setting times of the cement paste increased as the replacement with fine MSWI BA increased. However, the variation for less than $50 \%$ replacement was so small that it will hardly affect the requirements of construction.

(5) The pore volume in the paste samples shifted to those of pore diameters typical of $\mathrm{C}-\mathrm{S}-\mathrm{H}$ gel at later ages. Moreover, the fine MSWI bottom-ash pastes contained a higher proportion of fine pores than did the control pastes. Less than $50 \%$ replacement in Portland cements could affect early strength development but had no significant effect on the degree of hydration at later ages. Because of the larger amount of pozzolanic reaction products, the strength increased with decreasing porosity.

\section{Acknowledgments}

2011 Dalian Science and Technology Foundation (Project Number: 2011J21DW006), National Natural Science Foundation of China (Project Number: 51078051). 


\section{Open Access}

This article is distributed under the terms of the Creative Commons Attribution License which permits any use, distribution, and reproduction in any medium, provided the original author(s) and the source are credited.

\section{References}

Antiohos, S. K., \& Tsimas, S. (2007). A novel way to upgrade the coarse part of a high calcium fly ash for reuse into cement systems. Waste Management, 27(5), 675-683.

Bertolini, L., Carsana, M., Cassago, D., Quadrio Curzio, A., \& Collepardi, M. (2004). MSWI ashes as mineral additions in concrete. Cement and Concrete Research, 34(10), 1899-1906.

Bignozzi, M. C., \& Saccani, A. (2012). Ceramic waste as aggregate and supplementary cementing material: A combined action to contrast alkali silica reaction (ASR). Cement and Concrete Composites, 34(10), 1141-1148.

Chang, N. B., Wang, H. P., Huang, W. L., \& Lin, K. S. (1999). The assessment of reuse potential for municipal solid waste and refuse-derived fuel incineration ashes. Resources, Conservation and Recycling, 25(3-4), 255-270.

Cheeseman, C. R., Makinde, A., \& Bethanis, S. (2005). Properties of lightweight aggregate produced by rapid sintering of incinerator bottom ash. Resources, Conservation and Recycling, 43(2), 147-162.

Cheng, A. (2012). Effect of incinerator bottom ash properties on mechanical and pore size of blended cement mortars. Materials and Design, 36, 859-864.

Cheng, H. F., \& Hu, Y. N. (2010). Municipal solid waste (MSW) as a renewable source of energy: Current and future practices in China. Bioresource Technology, 101(11), 3816-3824.

Chimenos, J. M., Segarra, M., Fernandez, M. A., \& Espiell, F. (1999). Characterization of the bottom ash in municipal solid waste incinerator. Journal of Hazardous Materials, 64(3), 211-222.

Ferraris, M., Salvo, M., Ventrella, A., Buzzi, L., \& Veglia, M. (2009). Use of vitrified MSWI bottom ashes for concrete production. Waste Management, 29(3), 1041-1047.

Filipponi, P., Polettini, A., Pomia, R., \& Sirini, P. (2003). Physical and mechanical properties of cement-based products containing incineration bottom ash. Waste Management, 23(2), 145-156.

Gerven, T. Y., Keer, E. V., Arickx, S., Jaspers, M., Wauters, G., \& Vandecasteele, C. (2005). Carbonation of MSWI-bottom ash to decrease heavy metal leaching, in view of recycling. Waste Management, 25(3), 291-300.
Ginés, O., Chimenos, J. M., Vizcarro, A., Formosa, J., \& Rosell, J. R. (2009). Combined use of MSWI bottom ash and fly ash as aggregate in concrete formulation: Environmental and mechanical considerations. Journal of Hazardous Materials, 169(1-3), 643-650.

Juric, B., Hanzic, L., Ilic, R., \& Samec, N. (2006). Utilization of municipal solid waste bottom ash and recycled aggregate in concrete. Waste Management, 26(12), 1436-1442.

Kula, I., Olgun, A., Erdogan, Y., \& Sevinc, V. (2001). Effects of colemanite waste, cool bottom ash, and fly properties of cement. Cement and Concrete Research, 31(3), 491-494.

Lam, C. H., Barford, J. P., \& McKay, G. (2010). Utilization of incineration waste ash residues in Portland cement clinker. Chemical Engineering Transactions, 21, 757-762.

Lee, T. C., Wang, W. J., \& Shih, P. Y. (2008). Slag-cement mortar made with cement and slag vitrified from MSWI flyash/scrubber-ash and glass frit. Construction and Building Materials, 22(9), 1914-1921.

Li, X. G., Lang, L., Ma, B. G., Chen, Q. B., Yin, X. B., \& Jian, S. W. (2012). Utilization of municipal solid waste incineration bottom ash in blended cement. Journal of Cleaner Production, 32, 96-100.

Lin, K. L., Chang, W. C., \& Lin, D. F. (2008). Pozzolanic characteristics of pulverized incinerator bottom ash slag. Construction and Building Materials, 22(3), 324-329.

Müller, S., \& Rübner, K. (2006). The microstructure of concrete made with municipal waste incinerator bottom ash as an aggregate component. Cement and Concrete Research, 36(8), 1434-1443.

Pan, J. R., Huang, C., Kuo, J. J., \& Lin, S. H. (2008). Recycling MSWI bottom and fly ash as raw materials for Portland cement. Waste Management, 28(7), 1113-1118.

Pecqueur, G., Crignon, C., \& Quénéeb, B. (2001). Behaviour of cement-treated MSWI bottom ash. Waste Management, 21(3), 229-233.

Pera, J., Coutaz, L., Ambroise, J., \& Chababbet, L. (1997). Use of incinerator bottom ash in concrete. Cement Concrete, 27(1), 1-5.

Sorlini, S., Abba, A., \& Collivignarelli, C. (2011). Recovery of MSWI and soil washing residues as concrete aggregates. Waste Management, 31(2), 289-297.

Valle-Zermeño, R. D., Formosa, J., Chimenos, J. M., Martínez, M., \& Fernández, A. I. (2013). Aggregate material formulated with MSWI bottom ash and APC fly ash for use as secondary building material. Waste Management, 33(3), 621-627.

Yang, N., Zhang, H., Chen, M., Shao, L. M., \& He, P. J. (2012). Green house gas emissions from MSW incineration in China: Impacts of waste characteristics and energy recovery. Waste Management, 32(12), 2552-2560. 